\title{
Gastric Emptying Following Finney Pyloroplasty and Vagotomy
}

\author{
Jack R. Ludwick, MD, James N. Wiley and Paul Bass, PhD
}

\begin{abstract}
Gastric emptying was evaluated in a series of unanesthetized dogs in the intact state, following Finney pyloroplasty, and with the addition of vagotomy. Sodium chromate labeled test meals of glucose, trisodium citrate, and trisodium citrate-fat were used. Finney pyloroplasty resulted in a trend for delayed emptying of fat from the stomach. The trisodium citrate test meal increased the levels of gastric secretion after pyloroplasty.

Association of our previous motility data based on pyloroplasty studies with the current gastric-emptying evaluations indicate that too large a stoma between the antrum and duodenum is an impediment to normal gastric emptying of fatty meals.
\end{abstract}

Vagotomy and pyloroplasty is a current, definitive operation for patients with chronic peptic ulcer. Impaired gastric emptying in the early postoperative period is a recognized sequela of this procedure (1). We have questioned the impeditive nature of the Finney pyloroplasty and have demonstrated that the pyloroplasty alone significantly influences the antral-duodenal contractile activity (2). In conjunction with this work (2) and other evaluations of gastric emptying in our laboratory (3) we have utilized a serial test-meal procedure to assess the influence of Finney pyloroplasty and vagotomy on gastric emptying in the early postoperative period.

From the Department of Surgery, University of Michigan Medical Center; and Pharmacology Department, Medical and Scientific Affairs Division, Parke, Davis \& Co., Ann Arbor, Mich.

The authors appreciate the technical assistance of $\mathrm{Mr}$. James E. Copp, Department of Biostatics, Parke, Davis Research Labs.

Address for reprint requests: Dr. Jack R. Ludwick, Department of Surgery, University of Michigan Medical Center, Ann Arbor, Mich 48104.

\section{METHODS}

Animal preparation. Gastric emptying was measured in 5 beagle dogs (average weight, $11 \mathrm{~kg}$ ). The three conditions examined in each animal were: intact animals, animals with pyloroplasty, and animals with pyloroplasty and vagotomy. To facilitate repeated aspiration of gastric contents, a vitallium cannula was placed in the cervical esophagus (3). Tests in the intact animals were initiated 10 days after placement of the cannula. Following these tests, pyloroplasty $(2,4)$ was performed and again 10 days allowed for recovery before initating tests. The size of the pyloroplasty stoma was kept as constant as possible in a range of $4-5 \mathrm{~cm}$. About a month later, transthoracic vagotomy was performed and the gastric-emptying tests repeated. Assessment of gastric emptying was completed 2-3 weeks after each operative phase.

rest meal. Gastric emptying was measured by a modification of Hunt's method (5), which technic has been described (3). A nonabsorbable label consisting of sodium chromate $\left(\mathrm{Na}_{2} \mathrm{Cr}^{51} \mathrm{O}_{k}\right)$ in a concentration of $0.02 \mu \mathrm{c} / \mathrm{ml}$ was added to 200 milliosmolar solutions of trisodium citrate (citrate test meal), to glucose, or to trisodium citrate with $10 \mathrm{mN}$ oleic acid suspended by $0.5 \%$ Tween 80 (citrate-fat test meal). The three test meals had an equal osmolarity as measured by freezing-point depression. The initial $\mathrm{pH}$ of the citrate and 
citrate-fat test meals were similar (7.3-6.5) and were buffered due to the presence of trisodium citrate. The glucose test meal had a lower initial pH (4.6) and was not buffered. The test meals were at room temperature $\left(25^{\circ} \mathrm{C}\right)$ when administered.

Experimental procedure. For cach test day, the animals were fasted for $18 \mathrm{hr}$ and the stomach was rinsed with $100 \mathrm{ml}$ of distilled water through a plastic catheter inserted in the esophageal cannula. If, after repeated rinsings (2-3 times), food particles were still in the stomach, the dogs were eliminated from the experiment on that day. After rinsing, $300 \mathrm{ml}$ of one of the three labeled test meals were instilled into the stomach and the tube removed. Following a given time interval the tube was reinserted, the test meal aspirated, and the stomach rinsed with $50 \mathrm{ml}$ distilled water. The instillation and aspiration of the test meal were repeated three times per day at sequential time intervals of either 10,20 , and $40 \mathrm{~min}$ or 40,20 , and $10 \mathrm{~min}$. Thus, each time period is the interval between instillation and aspiration of a given test meal. This sequence of administration and aspiration of test meals was repeated at least two times in each animal for each of the three test meals and for each of the three conditions.

Following withdrawal of the test meal and noting the total volume of the aspirate, two $10-\mathrm{ml}$ aliquots from each time interval were counted for $3 \mathrm{~min}$ in a gamma spectrometer. Similar volumes of stock solution and the rinse solutions were counted for each experiment. The total volume passing the gastroduodenal junction (including endogenous secretion) was determined by subtracting the total amount of chromiumo1 withdrawn from the total amount of chromium51 instilled, this value being divided by the mean concentration of Cr51 during the time period of gastric emptying being evaluated. This method allowed the estimation of the total volume passing the gastroduodenal junction, the amount of endogenous secretion in this volume, and the instilled portion of the original $300 \cdot \mathrm{ml}$ test meal which left the stomach.

Data analysis. A 4-way analysis of variance with one random and three fixed factors (dogs) was used to analyze the characteristics of the original test meal and the endogenous secretions (6). The four parameters evaluated were: (1) conditions which compared the effects of intact animals to a surgical modification of the same animals by a pyloroplasty followed by a vagotomy; (2) the test meals of trisodium citrate, glucose, and crtrate-fat; (3) time periods which were 10,20 , and $40 \mathrm{~min}$; and (4) the dogs were considered as random criteria. Individual variations among dogs was not the point of interest as much as the fluctuates among the three conditions on the same dog. Tests for significance were based on Tukey multiplerange test.

\section{RESULTS}

Gastric emptying of test meals. With respect to time and surgical procedures (conditions) the volumes of the $300-\mathrm{ml}$ test meals leaving the stomach are graphically presented in Fig la.

The 4-way analysis of variance on the gastric-emptying data displayed that: 1. The conditions when pooled across test meals, time periods, and dogs had no effect on emptying. This lack of significance could be attributed to the positive interaction of condition versus test meals (Fig 2a). Animals with pyloroplasty tended to retain citrate-fat test meals. After vagotomy, the trend for delayed emptying returned to the normal rate (Fig 2a). 2. Each of the volumes of the three test meals leaving the stomach, pooled over conditions, time, and dogs as significantly different from each other. The mean pooled volumes leaving the stomach were 215.I, 151.9 , and $80.5 \mathrm{ml}$ for trisodium citrate, glucose, and citrate-fat test meals, respectively. 3. The volumes leaving the stomach in the three time periods, pooled over conditions, test meals, and dogs were significantly different. The volumes emptied for each time period were $100.5,150.4$, and $196.6 \mathrm{ml}$, respecitvely for 10,20 , and 40 $\mathrm{min}$. The interaction of the volume emptied for each test meal at each time period was significantly different-ie, the curves did not parallel each other (Fig 2b) .

Endogenous secretion. These consisted of the gastric secretion mixed with salivary and regurgitated small-bowel contents (Fig 1b). The content of bile in the endogenous secretion was not a measured 

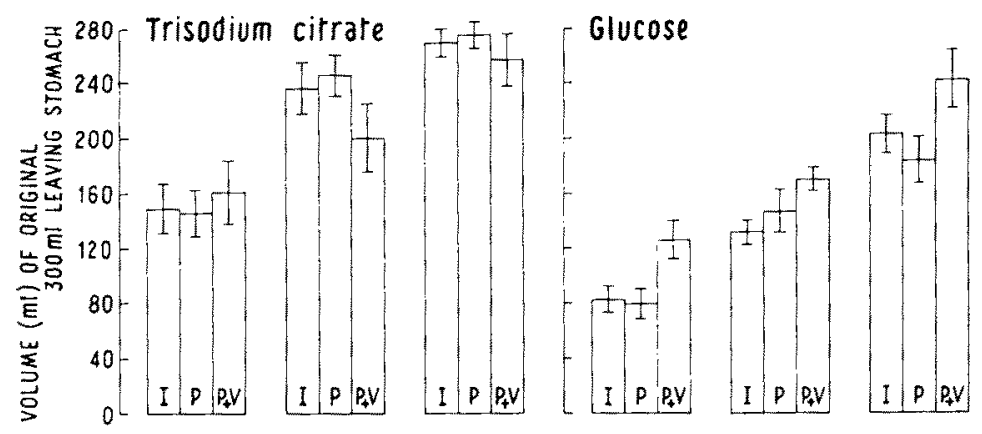

Trisodium citrate-fat

b. ENDOGENOUS SECRETIONS
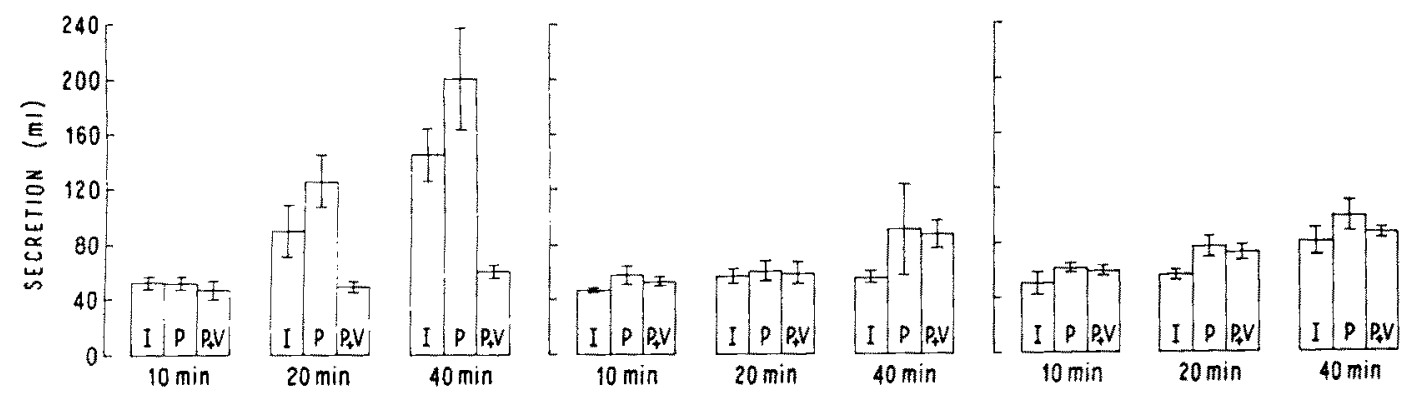

Fig la (top). Mean volumes $(\mathrm{ml})$ of original $300 \mathrm{mi}$ of three test meais leaving stomach under intact (I), pyloroplasty $(P)$, and pyloroplasty + vagotomy $(P+V)$ conditions for $10-20$, and 40 -min periods. Fig Ib (bottom). Mean volumes $(\mathrm{ml})$ of secretion elicited by three test solutions under three conditions for three time periods. Vertical lines represent mean standard errors.

parameter; however it was our impression that in the intact state only the occasional aspirate contained bile although, following pyloroplasty, bile was frequently seen in the aspirate. The performance of vagotomy on the dogs with pyloroplasty resulted in the occasional appearance of bile in the aspirate approaching the intact state.

The 4-way analysis of variance on the endogenous secretions demonstrated that: 1. The conditions had a significant effect on the mean pooled secretory volumes which were $70.2,91.2$, and $63.4 \mathrm{ml}$ in the intact, pyloroplasty, and pyloroplasty-withvagotomy conditions, respectively. The secretions were significantly greater in the pyloroplasty condition than in either the intact or pyloroplasty-with-vagotomy con- ditions. There was no significant difference between intact and pyloroplasty-with-vagotony conditions. 2. There was a significant difference between the volume of secretion elicited by the three test meals, pooled over conditions, time, and dogs. The respective grand means for trisodium citrate, glucose, and citrate-fat test meals were 91.2, 62.6 , and $70.9 \mathrm{ml}$. The trisodium citrate was different from both glucose and citratefat test meals and there was no significant difference between the latter two test meals. 3. The secretory volumes pooled over conditions, test meals, and dogs, with respect to the time periods were significantly dif: ferent from each other. The respective grand means for the 10-, 20-, and 40-min periods were $53.2,71.4$, and $100.1 \mathrm{ml}$. 

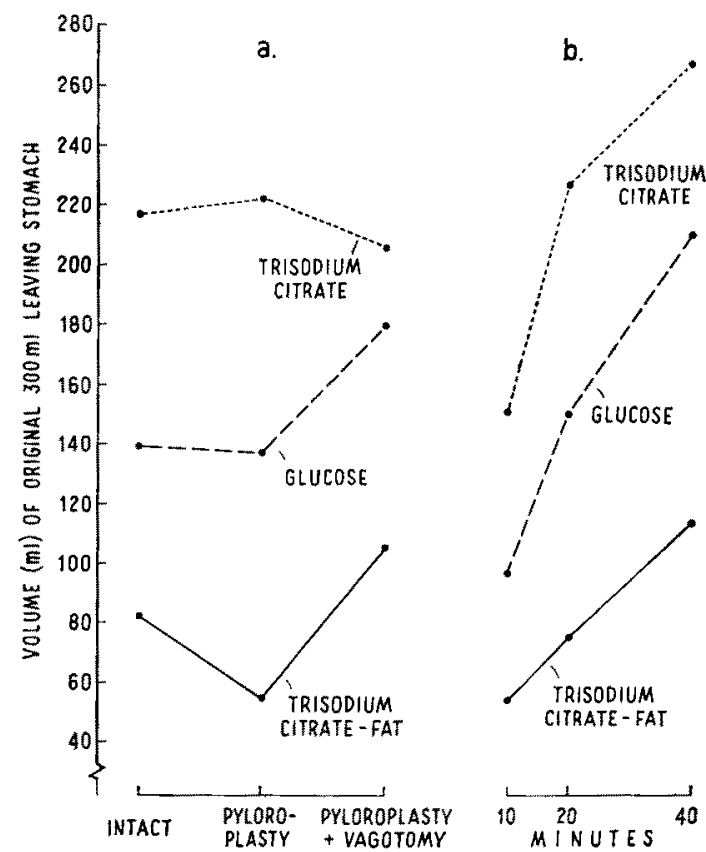

Fig 2a (left). Graphic representation of interaction of conditions versus test meals. Data were summed across dogs and time. Note trend of delayed emptying of citrate* fat test meal after pyloroplasty. Fig 2b (right). Graphic representation of interaction of time periods versus test meals. Data were summed across dogs and conditions.

Animal response and autopsy findings. Following pyloroplasty alone, the dogs ate without difficulty; however these dogs came to the majority of the experiments with retained food particles. Two dogs had intermittent episodes of vomiting and at the time of sacrifice, both demonstrated dilatation of the antral-duodenal area comprising the pyloroplasty. At autopsy, the pyloroplasty stomas in these dogs measured 7.0 and $5.5 \mathrm{~cm}$. These were larger than the size (approximately $4.5 \mathrm{~cm}$ ) we attempted to construct at the time of surgery. These latter 2 animals tended to retain more food particles than the other 3 animals in the study. Autopsy on the other 3 animals (stoma, approximately $4.5 \mathrm{~cm}$ ) did not demonstrate dilatation of the antral-duodenal area. The addition of vagotomy tended to increase the retention of food as observed at the time of the preexperiment stomach rinse. Confirmation of complete intrathoracic vagotomy was confirmed at autopsy.

The $\mathrm{pH}$ of the aspirated test meals are shown in Table 1. In the intact animals, the aspirated test meals containing the trisodium citrate were buffered by its presence and consequently had a higher $\mathrm{pH}$ than glucose test meals. For each test meal the $\mathrm{pH}$ data on the conditions were subjected to an analysis of variance and a Duncan's multiple-range test. The results were: the $\mathrm{pH}$ of aspirates from intact animals was not significantly different from that of the animals with pyloroplasty, but the $\mathrm{pH}$ of aspirates obtained from the animals following the vagotomy was significantly different from the other two conditions. Presumably this higher $\mathrm{pH}$ of the latter is due to the lack of endogenous secretions caused by the vagotomy.

Table 1. pH of Aspirated* Test Meals

\begin{tabular}{|c|c|c|c|c|c|c|c|c|c|}
\hline \multirow[b]{2}{*}{ Condition } & \multicolumn{3}{|c|}{ Citrate } & \multicolumn{3}{|c|}{ Glucose } & \multicolumn{3}{|c|}{ Citrate-fat } \\
\hline & $10 \mathrm{~min}$ & $20 \mathrm{~min}$ & $40 \mathrm{~min}$ & $10 \mathrm{~min}$ & $20 \mathrm{~min}$ & $40 \mathrm{~min}$ & $10 \mathrm{~min}$ & $20 \mathrm{~min}$ & $60 \mathrm{~min}$ \\
\hline Intact & $6.3 \pm 0.1$ & $5.5 \pm 0.4$ & $3.8 \pm 0.5$ & $2.7 \pm 0.4$ & $2.3 \pm 0.2$ & $2.1 \pm 0.1$ & $6.1 \pm 0.1$ & $5.7 \pm 0.2$ & $5.4 \pm 0.2$ \\
\hline $\begin{array}{l}\text { Pyloroplasty } \\
\text { Pyloroplasty }\end{array}$ & $5.9 \pm 0.3$ & $4.8 \pm 0.5$ & $3.6 \pm 0.7$ & $2.7 \pm 0.3$ & $2.1 \pm 0.2$ & $2.1 \pm 0.2$ & $5.9 \pm 0.1$ & $6.0 \pm 0.0$ & $5.8 \pm 0.1$ \\
\hline + vagotomy & $6.8 \pm 0.1$ & $6.8 \pm 0.1$ & $6.7 \pm 0.2$ & $4.6 \pm 0.3$ & $4.8 \pm 0.4$ & $5.0 \pm 0.4$ & $6.4 \pm 0.1$ & $6.3 \pm 0.1$ & $6.1 \pm 0.2$ \\
\hline
\end{tabular}

* The initial $\mathrm{pH}$ for the three test meals were: $7.3,4.6$, and 6.5 , respectively. 


\section{DISCUSSION}

We have previously demonstrated that the contractile activity of the antrum and duodenum is distinctly altered by Finney pyloroplasty (2), These findings indicated that with pyloroplasty the normal "antral contraction-duodenal inhibition" reflex was abolished and the two areas contracted simultaneously. During these investigations (2) it became apparent that gastric emptying was also influenced by pyloroplasty. In this study the impeditive nature of the Finney pyloroplasty was assessed with liquid serial test meals. Unfortunately there is no good method to monitor quantitatively normally ingested food, but the solutions used do provide some index of gastric emp. tying.

An interesting response was the trend for impaired emptying of fat (oleic acid) after pyloroplasty. The 10 min evaluation displayed no differences between the emptying of oleic acid in the intact and the pyloroplasty states. This would indicate that an interval of time is required before these differencs in response are apparent. We feel that fat receptors in the duodenal mucosa are overloaded by the amount of fat passing through the pyloroplasty stoma, which fact in turn results in decreased gastric emptying. Our studies do not demonstrate the location of the fat receptors in the duodenum. This response requires $10-20 \mathrm{~min}$ to develop and presumably is mediated through the release of enterogastrone from the duodenal mucosa. Apparently, the size of the pyloroplasty stoma infuences the amount of fat or other substance flooding the duodenal mucosa at a given time. The clinical impression of delayed gastric evacuation of a fat meal following a drainage procedure has been reported (7) .

Additional gastric-emptying investiga- tions on intact animals from this laboratory (3) have confirmed the slower gastric emptying of oleic acid than of the other test meals. In this work (3), the ingestion of fat displayed decreased antral and increased duodenal contractile activity. This pattern would tend to delay gastric emptying since intraluminal contents move from areas of high to areas of low activity. In contrast to the fat test meal, the citrate test meal left the stomach most rapidly and resulted in stimulation of antral contractile activity with inhibition of duodenal contractile activity.

Lawson and Dragstedt (8) have recently demonstrated that the increased gastric secretion due to antral stasis following vagotomy is not completely abolished by Heineke-Mikulicz pyloroplasty. There was a decrease in Heidenhain secretions in vagotomized dogs following pyloroplasty and the secretions did not return to control or prevagotomy levels. These findings lend further support to the concept of altered antral-duodenal contractile activity leading to impaired gastric emptying following pyloroplasty. The investigation of Lawson and Dragstedt did not consider Finney pyloroplasty; however, we would anticipate from our observations of increased secretory volumes with citrate test meals following pyloroplasty that similar data would be obtained from detailed secretion studies with Finney pyloroplasty.

It was of interest that following vagotomy the emptying of oleic acid from the stomach returned to prepyloroplasty (intact) levels. This occurred despite the fact that these animals frequently came to the test situation with retained food particles in the stomach after an 18-24-hr fast. This again emphasized that the emptying of solid and liquid substances from the stomach may not be an identical process. The intact vagus is apparently required for the 
delayed emptying of oleic acid after pyloroplasty alone. Although the mechanism is obscure, it may well be the loss of afferent fibers by vagus section which abolishes an abnormal reflex situation induced by Finney pyloroplasty.

Relating our motility evaluation of the gastroduodenal area with the gastricemptying studies, we feel that the Finney pyloroplasty definitely alters the normal relationships between antrum and duodenum. The antrum and first portion of the duodenum are converted to one large compartment. This would interfere with the normal antral pump mechanism (9). The coordinated "antral contractionduodenal inhibition" motility cycle is abolished, reducing the pressure differential between these two areas. Further, the duodenum and related receptors may be initially subjected to flooding by a greater than normal amount of gastric content. This creates an abnormal reflex which in turn interferes with gastric emptying. In part, this may be due to fat receptors in the duodenum that temporarily become overwhelmed. The exact type or number of duodenal receptors influenced by alterations due to pyloroplasty have not been defined.

Without attempting widespread clinical correlation from our animal data, we feel that some of the clinical features seen after Finney pyloroplasty may well be due to altered motility of the gastroduodenal area. The size of the stoma in the Finney pyloroplasty is larger than is consistent with normal gastric emptying. Further, several clinical evaluations $(10,11)$ have noted that the recurrence rate of ulcer is greater following pyloroplasty and vagotomy than following some of the other definitive ulcer operations. Our data and those of Lawson and Dragstedt (8) indicate that a degree of impaired emptying can result in gastric retention in amounts that may be undesirable in the care of ulcer disease. We are not condemning pyloroplasty and vagotomy in the treatment of peptic ulcer. However, definite alterations in motility and gastric emptying do occur in the dog following pyloroplasty (2). We therefore encourage at consideration of the size of the stoma when constructing a pyloroplasty.

\section{REFERENCES}

1. Fry WJ, Thompson NW: Vagotomy and pyloroplasty for duodenal ulcer. Surg Clin $\mathrm{N}$ Amer $46: 359,1966$

2. Ludwick JR, Wiley JN, Bass P: Pyloroplasty and vagotomy: Early effects on antral and duodenal contractile activity. Arch Surg (Chicago) 99:553, 1969

3. Weisbrodt NW, Wiley $J \mathrm{~N}$, Overholt BF. et al: A relation between gastroduodenal muscle contractility and gastric emptying. Gut 10:543, 1969

4. Kraft RO, Fry WJ: Operative technic of selective gastric vagotomy. Amer J Surg $105: 423,1963$

5. Hunt JN: Gastric emptying and secretion in man. Physiol Rev 39:491, 1959.

6. Chilton NW: Studies in the design and analysis of dental experiments. II. A fourway analysis of variance. J Dent Res 39: 344,1960

7. Waddell WR, Wang CC: Effect of vagotomy on gastric evacuation of high fat meals. J Appl Physiol 5:705, 1953

8. Lawson LJ, Dragstedt LR II: Vagotomypyloroplasty effects on antrum function. Arch Surg (Chicago) 96:109, 1968

9. Hunt JN: Control of gastric emptying, Amer J Dig Dis 13:371, 1968

10. Silberman VA, Winkley JH: Surgical treatment of peptic ulcer. Arch Surg (Chicago) $97: 84,1968$

11. Burdette WI, Rasmussen BL, Fitzpatrick WK: Management of duodenal ulcer by vagus resection and pyloroplasty. Surg Gynec Obstet 127:513, 1968 